\title{
Quality Management Essentials and the Importance of Smallholder Farmers Collaborating
}

\author{
Peter J. Batt \\ International Institute of Agrifood Security \\ Curtin University \\ Perth \\ Australia
}

\begin{abstract}
If smallholder farmers are to transact with modern institutional markets, they must first learn to collaborate. Collaboration provides a mechanism for smallholder farmers to improve their offer quality, ensuring that they have a sufficient quantity and range of product to meet the buyers' specifications. These product specifications are often highly variable, depending on the product itself, the manner in which the customer intends to use it and the quantity of product available in the market. However, in institutional markets, the quality construct itself is evolving, as more buyers seek assurances that the product is safe to eat and has been produced using sustainable and ethical production practices. Country-of-origin labelling and provenance are emerging as indicators of quality signalling superior quality attributes such as food safety, taste or a reduced carbon footprint. Changing consumer demands offer more opportunities for smallholder producers to augment the offer quality through innovative packaging and more convenient products.
\end{abstract}

\section{INTRODUCTION}

To improve rural livelihoods an integrated approach is required to facilitate the greater participation of smallholder farmers. Collectively, smallholder farmers produce some 80 percent of the food consumed in Asia and sub-Saharan Africa (Altieri and Koohaflan, 2008). However, their economic viability is being threatened by globalization and relentless competitive pressures from downstream customers. Smallholder farmers may choose to withdraw and become subsistence producers, or to consolidate and form larger enterprises that can compete (FAO, 2012).

Acting independently, smallholder farmers have limited access to production inputs. At the household level, most smallholder farmers simply do not have the funds to purchase good quality seed, fertilisers and pesticides. In those circumstances where smallholder farmers must procure production inputs, with little to no collateral, most are forced to borrow from downstream market intermediaries at extraordinarily high rates of interest. At the village or community level, retailers may not stock the desired inputs because of the limited demand or the inability of most smallholder farmers to pay.

Geographic isolation, distance and travel time often mean that smallholder farmers have limited access to appropriate knowledge and technology. Inadequate crop rotations often result in the build-up of soil borne disease, greatly reducing yields, which farmers try to compensate for by adding more fertilisers. With limited knowledge of pests and diseases, farmers apply the wrong chemicals, and when the application fails to deliver the desired result, the rate of application is increased. Poor application techniques not only reduce the efficacy of the chemical but expose the farmers to considerable personal risk from the ingestion or absorption of the chemical. 
Geographic isolation and distance from markets can also limit smallholder farmers access to market information. Supply chains are often long and protracted, meaning that not only the farmers but also the market intermediaries with whom they transact are physically isolated from the ultimate buyer. Farmers often don't know what the customer wants nor are they aware of how the way they have harvested, processed and packed their product determines the appearance and acceptability of the product in the market. As market prices are determined primarily by supply and demand, ideally, farmers need to know what area has been planted in each product and the demand for that product. However, with limited access to credit and technical advice, most smallholder farmers are unable to respond to the market signals. Cognisant of the risks, many farmers plant in the hope that some natural event will dramatically reduce the supply from another production area leading to extraordinarily high prices.

Most significant however, by continuing to act independently, smallholder farmers are unable to engage with modern institutional buyers. Without being able to supply a sufficient quantity and range of good quality product at a competitive price, most institutional buyers will look elsewhere, even preferring, in some instances, to import. However, by learning to work collaboratively, smallholder farmers can improve their offer quality.

\section{OFFER QUALITY}

Derived from industrial purchasing theory, the concept of offer quality describes how buyers in business-to-business markets endeavour to find least cost solutions which best satisfy functional criteria (Batt and Morooka, 2003). Quality, price and the ability to deliver reliably and consistently are generally regarded as the most important criteria by which organizational buyers evaluate potential suppliers (Cunningham and White, 1973; Lehmann and O'Shaughnessy, 1974; Dempsey, 1978; Wilson, 1994).

In business-to-business markets, quality is a customer determination based upon the customer's actual experience with the product measured against the customer's stated requirements (Feigenbaum, 1991). Here it is important to understand that quality does not mean best: quality means "fitness for the intended purpose". Using potatoes as an example, the criteria employed in purchasing potatoes for processing are very different than when purchasing potatoes for table consumption. Even for table consumption, the selection criteria can be very different depending upon how the executive chef intends to prepare and present the cooked potatoes. Not unexpectedly, there is some relationship between quality and cost, with buyers paying particular attention to the costs of product failure and the inability of upstream suppliers to deliver reliably and consistently. Furthermore, in what has become a saturated and highly competitive market, the concept of quality continues to expand as firms endeavour to differentiate their product offer.

Peri (2006) provides perhaps the most comprehensive definition of food quality, describing the different attributes of quality under one of seven major categories:

\section{Food safety}

There is an implicit assumption that any food product purchased for resale or as a food ingredient in the manufacture of some other product is safe for consumption. To protect their brand, most of the world's major retailers and food manufacturers now require their suppliers to have third party certified quality assurance systems to protect against the accidental and deliberate contamination of the product (Batt, 2006). 
While fresh fruit and vegetables are generally perceived to be healthy and nutritious, there is a high risk of chemical, micro-biological and physical contamination. Chemical contamination can occur from the presence of heavy metals in soil and irrigation water, the excessive application of nitrate fertilisers and pesticides, the nonprescribed use of pesticides, the failure to observe withholding periods, and the use of banned chemicals (Shepherd and Tam, 2008). Problems are often compounded by the inability of farmers to read the label and the subsequent re-use of packaging materials to transport products to market.

Microbial contamination may arise from the use of irrigation water contaminated by sewage of fouled by wildlife, the use of untreated farmyard manure, poor personal hygiene, and unclean workplaces (Shepherd and Tam, 2006). For fresh produce, the most common physical contaminant is soil, but often intermingled with the product is a great variety of other foreign materials, many of which have been purposefully added to increase the weight. In manufactured food products, the two major contaminants are glass and metal fragments which are inadvertently added during the manufacturing process.

\section{Commodity requirements}

The commodity requirements are established by law, voluntary regulations or customary practices (Peri, 2006). These generally describe the physical attributes of the product in terms of shape, size and colour, freedom from blemishes, cuts and abrasions, freshness and firmness, but they may also relate to other internal characteristics such as maturity, brix, acidity or specific gravity.

Increasingly, these quality requirements are being established by the customer, depending upon how the customer intends to use the product. Using potatoes again as an example, an executive chef in Asia may choose imported Russet Burbank for French fries or baking, and Granola for curries or mash. For potato salads, the chef will prefer smaller tubers, whereas for French fries, larger tubers are preferred.

Institutional buyers generally have written standards to guide and assist potential suppliers, but these standards are highly subjective and very much dependent on the quality of the fresh produce available. When there is a shortage, to secure a sufficient quantity of product to meet the anticipated demand, the standards may be relaxed, but when supply is plentiful, the standards will be rigidly enforced (Batt et al., 2011). To reduce costs and preparation time in the kitchen, not only must the product be washed, trimmed and any external packaging removed, but for products such as garlic, ginger and onions, the product may need to be peeled.

\section{Nutritional requirements}

A diet rich in fresh fruit and vegetables has been linked to a reduced risk of chronic diseases such as cancer, heart disease and stroke (van Duyn and Pivonka, 2000). Evidence is also emerging to support the positive role of increased fresh fruit and vegetable consumption in reducing the risk of cataracts, diverticulosis, pulmonary disease and hypertension. Antioxidants such as carotenoids, flavonoids and Vitamin $\mathrm{C}$, the sulphur containing compounds in the allium family, and the dithiothiones, indoles and isothiocyanates found in the cruciferous vegetables are all thought to play some role in protecting the body from disease. Furthermore, consumers are increasingly turning towards products with low fat, low sugar, no preservatives and no artificial colours or flavour enhancers (Prescott et al., 2002). 


\section{Sensory requirements}

Quality is the key concept in building customer value and satisfaction. For food taste is the most important experience attribute (Oude Ophuis and van Tripp, 1995). However, empirical studies have consistently revealed that most consumers are unable to accurately judge the eating quality of fruit from an evaluation of the external product features (HRDC 1990; Batt and Sadler, 1999). Harker et al. (2002) describes how two pieces of fruit growing side by side on the same tree may develop very different levels of sweetness, acidity, flavour and texture. Furthermore, the taste and eating quality will vary between growers, growing regions, varieties and over time as the product ages, both in storage and on the retail shelf. For buyers, this inherent variation in product quality and the inability to select fruit that consistently delivers the desired eating experience will lead to dissatisfaction and potentially, to a reduction in the quantity of fruit purchased.

The consumer preference for fruit is derived from the interaction between taste, texture and flavour (Harker, 2001). Texture relates to the mechanical properties of the flesh, mouth-feel and juiciness. However, Codron et al. (2005) consider that appearance should also be considered as a sensory attribute, for there is anecdotal evidence to suggest that most consumers "eat with their eyes". Sijtsema et al. (2002) suggest that taste is based on the observation of the food, and is influenced by the environment, geography, demography, socio-demography and psychological variables. Peri (2006) further expands on the sensory attributes to include memory, culture, values and emotions, for these bring together the consumer's knowledge or memory of food and the consumer's sensory reactions to it.

\section{Production and ethical requirements}

Increasingly, consumers want to know that their food is safe, where it came from, how it was produced and who handled it (Martech, 2005). In Asia, county-of-origin is currently perceived to be the most important piece of information consumers require in their decision to purchase a particular food product (Batt, Noonan and Kenyon, 2006). For the purchase of fresh fruit and vegetables, origin information is sought mainly for the reasons of: (1) eating quality (von Alvensleben and Meier, 1990); (2) food safety (Pirog and Larson, 2007) and (3) to support local producers (Nygard and Storstad, 1998).

Furthermore, consumers are showing a greater interest in the ethical aspects of food production, which includes organic agriculture, concern for the environment, animal welfare and worker welfare (Becker, 1999; Peri, 2006). Organic farming practices involve natural production systems (without chemicals) that lessen the social and ecological impact of agricultural production systems on the environment. Yiridoe et al. (2005) demonstrate that in comparing organically grown and conventionally grown produce, organic production protocols place more importance on animal welfare, environmental impact, genetic modification, pesticide use and worker welfare.

\section{Food guarantees}

Proof of claims is becoming a key requirement in most institutional markets, especially with regard to food safety and the various credence attributes such as how the product was produced, the means by which it was processed, the environmental quality or social equity (Batt, 2007). Labelling is also required to provide nutritional information, to identify what components have been added to the food, including the presence of genetically modified organisms, and the best-before or use-by date. 


\section{Food product packaging}

The product packaging system must protect the product, facilitate product recognition, marketing and use. The quality associated with packaging includes aesthetic requirements, presentation and the information conveyed by the label (Peri, 2006).

\section{COLLABORATIVE MARKETING}

While most smallholder farmers are readily able to transact with traditional wholesale and retail markets, their experiences in selling to modern institutional markets are vastly different. Unable to maintain a consistent supply of good quality product and unable to perform many of the value-added activities demanded by their customers, smallholder farmers are often excluded from participating in the institutional market. While there are numerous impediments including the lack of infrastructure, appropriate inputs, knowledge and technical advice, micro-finance and market information (Chen, Shepherd and da Silva, 2005), one of the mechanisms most often advocated to facilitate their inclusion into these high value markets is the formation of collaborative marketing groups.

Collaborative marketing groups have traditionally been established to increase the bargaining power of members or to take advantage of the economies of scale associated with downstream processing (Murray-Prior, 2007). However, other reasons have included the desire to take advantage of government policies or to capture additional returns from diversifying the business.

For smallholder farmers, the key benefits of collaborative marketing arrangements can be grouped into two main categories: economic and social. Most smallholder farmers expect to achieve an economic advantage from collaboration through the higher price that they receive from consolidating, grading and sorting sufficient product to meet the needs of their downstream buyers (Batt et al., 2011). However, the benefits of collaborative marketing can also enhance smallholder farmers' net returns through reducing costs. Not only does consolidation reduce the costs of transport, but the collective purchase of production inputs also has the potential to lower costs

As few extension agencies have the funds to offer advice to individual farmers, collaboration greatly improves smallholder farmers' access to technical information. Other support organisations often facilitate the linkage between collaborative marketing groups and institutional buyers by funding market research and visits to prospective buyers. Others offer assistance with logistics and packaging (Batt et al., 2011).

Even although collaborative marketing does not always provide a higher price, group members have reported that they have a much better understanding of the market dynamics, the role and function of market intermediaries, and what they need to do to satisfy their buyers' demands (Montiflor, Batt and Murray-Prior, 2008). This has resulted in a greater ability to negotiate with downstream buyers and a vastly improved relationship leading to higher levels of trust, not only between the group and the focal buyer, but also between the group members themselves. Group members feel more empowered, for they are able to apply the skills learnt in transacting with the focal customer to other markets.

One of the most significant benefits of collaborative marketing is access to working capital (Batt et al., 2011). Through collaborative marketing groups, more so when the group is linked to an institutional buyer, micro-financiers are able to spread their risk by advancing a group loan, whereby each member of the group becomes partly responsible for the other members loans. 
In communities where the group has an assured market for their product, smallholder farmers will often increase the area planted in the focal crop, with a parallel increase in the demand for labour associated with cultivation, planting, harvesting and sorting. Other entrepreneurs within the community gain employment in facilitating the transport of the produce (Batt et al., 2011).

At the community level, the formation of collaborative marketing groups can have a significant positive impact in bringing the community closer together. As sales increase, the community begins to recognise that its greatest strength lies within the community itself. Through acting collaboratively, individual households can achieve more than if they acted independently. However, such will only occur where there is trust, financial transparency and effective leadership (Batt et al., 2011).

Many of the collaborative marketing groups have implemented a voluntary levy where $5-10 \%$ of the sales revenue is collected to establish a revolving fund. Members are able to access these funds to purchase production inputs or to meet unforeseen household expenses (Batt et al., 2011). Furthermore, a strong rural community often attracts financial support from other sources. International development agencies often make significant public investments in infrastructure including sanitation and water supply, packing sheds and equipment. Some collaborative marketing groups have been provided with funds to pay for the salaries of both full-time and part-time staff and/or a vehicle.

In response to adverse climatic conditions, many smallholder farmers are adopting low input biodynamic farming practices. This includes the use of open pollinated seeds, fermented plant juices and extracts, vermi-compost, companion planting, integrated pest control, crop rotations and contour planting (Batt et al., 2011). This has resulted in a significant reduction in the use of chemical fertilisers, pesticides and herbicides. With appropriate crop rotations, as less chemical is applied to control pests and diseases, there is less runoff to contaminate streams and waterways, less likelihood of farmers becoming accidentally poisoned and less likelihood that the produce itself will be contaminated by chemical residues.

\section{Literature Cited}

Altieri, M.A. and Koohaflan, P. 2008. Enduring farms: climate change, smallholders and traditional farming communities. Third World Network.

Batt, P.J., Concepcion, S.B., Lopez, M.T., Axalan, J.T., Hualda, L.A.T. and Montiflor, M.O. 2011. Exploring the institutional market for fresh vegetables in the Southern Philippines. Acta Hort 895: 59-68.

Batt, P.J., Concepcion, S.B., Murray-Prior, R.B. and Israel, F.T. 2011. Experiences in Linking Smallholder Vegetable Farmers to the Emerging Institutional Market in the Philippines. Acta Hort 921: 57-63.

Batt, P.J. 2007. Expanding the quality concept: an holistic approach in Batt, P.J. and Cadilhon (ed), Proceedings of an International Symposium on Fresh Produce Supply Chain Management. Dec 6-10, Lotus Pang Suan Kaew hotel, Chiang Mai, Thailand. RAP Publication 2007/21. FAO. Bangkok: 281-290.

Batt, P.J., Noonan J. and Kenyon, P. 2006. Global trends analysis of food safety and quality systems for the Australian food industry. A report submitted to Department of Agriculture, Fisheries and Forestry, Canberra.

Batt, P.J. 2006. Fulfilling customer needs in agribusiness supply chains. Acta Hort 699: 83-90. 
Batt, P.J. and Morooka, R. 2003. Perceptual differences in offer quality between Western Australian rock lobster exporters and Japanese rock lobster importers. Supply Chain Management; an Intl J, 8(5): 476-484.

Batt, P.J. and Sadler, C. 1999. Labels on apples; winners and losers In Cadeaux, J. and Uncles, M. (ed). Marketing in the Third Millennium: Proceedings of ANZMAC 99. UNSW.

Becker, T. 1999. The economics of food quality standards. Second Interdisciplinary Workshop on Standardisation Research, University of the Federal Armed Forces Hamburg.

Chen, K., Shepherd, A.W. and da Silva, C. 2005. Changes in food retailing in Asia: implications of supermarket procurement practices for farmers and traditional marketing systems. AGSF Occasional Paper 8. FAO Rome.

Codron, J-M., Grunert, K., Giraud-Heraud, E., Soler, L-G. and Regmi, A. 2005. Retail sector responses to changing consumer preferences: the European experience. In Regmi, A. \& Gehlbar, M. (eds). Global Markets for High-Value Food Products, Agricultural Information Bureau, Washington, D.C., USDA-ERS. 32-46.

Cunningham, M.T. and White, J.G. 1973. The determinants of choice of supplier. European J. of Marketing, 7: 189-202.

Dempsey, W.A. 1978. Vendor selection and the buying process. Industrial Marketing Management, 7: 257-267.

FAO. 2012. Smallholders and family farmers. Sustainability Pathways.

Feigenbaum, A.V. 1991. Total Quality Control. Third Ed. McGraw Hill.

Harker, F.R. 2001. Consumer response to apples. Proceedings Washington Tree Fruit Postharvest Conference. http://www.postharvest.tfrec.wsu.edu/proc/PC2001V.pdf.

Harker, F.R., Gunson, F.A., Brookfield, P.L. and White, A. 2002. An apple a day: the influence of memory on consumer judgement of quality. Food Quality and Preference. 13. $173-179$.

HRDC. 1990. Consumer study of the fruit and vegetable market. Horticulture Research and Development Corporation. Sydney.

Lehmann, D.R. and O'Shaughnessy, J. 1974. Differences in attribute importance for different industrial products. J. of Marketing, 38(April): 36-42.

Martech Consulting. 2005. Trends that impact New Zealand's horticultural food exports. Growing Futures case study series. [on-line] www.martech.co.nz

Montiflor, M.O., Batt, P.J. and Murray-Prior, R. 2008. Cluster farms in Mindanao, Philippines: Do vegetable farmers get what they expect? Banwa 8(2): 10-21.

Murray-Prior, R. 2007. The role of grower collaborative marketing groups in developing countries. Stewart Postharvest Review: 6:9.

Nygard, B. and Storstad, O. 1998. De-globalisation of food markets? Consumer perceptions of safe food: The case of Norway. European Society for Rural Sociology 38(1): 35-53.

Oude Ophuis, P.A.M. \& van Tripp, H.C.M. 1995. Perceived quality: a market driven and consumer oriented approach. Food Quality and Preference. 6: 177-183.

Peri, C. 2006. The universe of food quality. Food Quality and Preference 17: 3-8.

Pirog, R. and Larson, A. 2007. Consumer perceptions of the safety, health, and environmental impact of various scales and geographic origin of food supply chains. Leopold Center for Sustainable Agriculture. 
Prescott, J., Young, O., O’Neill, L., Yau, N.J.N. and Stevens, R. 2002. Motives for food choice: a comparison of consumers from Japan, Taiwan, Malaysia and New Zealand. Food Quality and Preference 13: 489-495.

Shepherd, A.W. and Tam, P.T.G. 2008. Improving the safety of marketed horticultural produce in Asia with particular reference to Vietnam. Acta Hort 794: 301-308.

Sijtsema, S., Linnemann, A., Van Gaasbeek, T., Dagevos, H. and Jongen, W. 2002. Variables influencing food perception reviewed for consumer-oriented product development. Critical Reviews in Food Science and Nutrition 42(6): 565-581.

van Duyn, M.A.S. and Pivonka, E. 2000. Overview of the health benefits of fruit and vegetable consumption for the dietetics professional: selected literature. J American Dietetics Assn. 100(12): 1511-1521.

von Alvensleben, R. and Meier, T. 1990. The influence of origin and variety on consumer perception. Acta Horticulturae 259: 151-161.

Wilson, E.J. 1994. The relative importance of supplier selection criteria: a review and update. Intl J. of Purchasing and Materials Management, Summer: 35-41.

Yiridoe, E.K., Bonti-Ankomah, S. and Martin, R.C. 2005. Comparison of consumer perceptions and preference toward organic versus conventionally produced foods: A review and update of the literature. Renewable Agriculture and Food Systems, 20: 193-205. 